\title{
Comparison of preemptive and non-preemptive renal transplant recipients with diabetes in terms of coronary artery disease and long-term survival
}

\author{
Umut KARABULUT ${ }^{1}$ and Kudret Keskin ${ }^{2}$ \\ ${ }^{1}$ Acibadem Hospitals Group \\ ${ }^{2}$ Sisli Hamidiye Etfal Training and Research Hospital
}

August 22, 2020

\begin{abstract}
Background Patients with end-stage renal disease have an increased risk of cardiac events. Although preemptive renal transplantation decreases mortality that is associated with dialysis, coronary artery disease remains as the primary cause of mortality even after transplantation. In this context, diabetic patients are more prone to adverse cardiac events. We aimed to compare the incidence of coronary artery disease and long-term survival rates in preemptive and non-preemptive diabetic renal transplantation recipients. Methods Diabetic patients with end-stage renal disease who underwent coronary angiography before renal transplantation were included retrospectively. These patients were divided into two groups as preemptive and non-preemptive according to transplantation strategy. Angiographic findings, particularly the severity of coronary artery disease, were compared between the two groups. Long-term all-cause mortality rates were also compared. Results A total of 164 patients were included in the study. Of these patients, 125 (78\%) were male, and the median age was 54 (Q1-Q3=45-59). The extent of coronary artery disease, revascularization rates SYNTAX and Gemini scores were similar between the two groups (all p $>0.05$ ). During 4,8 years of follow-up was there was no statistical difference in all-cause mortality rates $(\mathrm{HR}=0.59,[0.20-0.71], \mathrm{p}[\mathrm{log}-\mathrm{rank}]=0,33)$. Multivariate Cox regression analysis revealed that only age and hyperlipidemia were predictive of all-cause mortality $(\mathrm{HR}=1.03$ [1.001-1.07], $\mathrm{p}=0.04$ and $\mathrm{HR}=2.75$ [1.20-6.28], $\mathrm{p}=0.01$ respectively) Conclusion The prevalence, severity and revascularization rates of coronary artery disease were similar between the preemptive and non-preemptive diabetic renal transplant recipients. Also, there was no statistical difference in all-cause mortality rates during long-term follow-up. Keywords Kidney, coronary, diabetes, transplantation, preemptive What's known? : Although preemptive kidney transplantation is advantageous since dialysis is not applied, cardiovascular diseases are the most important cause of morbidity. What's new: Comparison of patients with and without preemptive transplantation in the diabetic patient group in terms of coronary artery disease and survival has not been performed
\end{abstract}

Comparison of preemptive and non-preemptive renal transplant recipients with diabetes in terms of coronary artery disease and long-term survival

Umut Karabulut M.D*1,Kudret Keskin Assoc.Prof ,M.D2

1Acıbadem International Hospital,Istanbul,Turkey

2İstanbul Şişli Hamidiye Etfal Education and Research Hospital,İstanbul,Turkey

*Corresponding-author:Umut Karabulut

e-mail:umkarabulut@gmail.com

Mail adress: Yesilkoy Istanbul Street,no:82,34149,Bakırkoy,Istanbul 
Telephone: +9005063509736

This study aimed to compare coronary artery disease and long-term survival rates in patients with diabetes according to whether they did or did not receive preemptive renal transplantation

\section{Hosted file}

abstract-2.edited.docx available at https://authorea.com/users/351988/articles/476380comparison-of-preemptive-and-non-preemptive-renal-transplant-recipients-with-diabetesin-terms-of-coronary-artery-disease-and-long-term-survival

\section{Hosted file}

maintext.docx available at https://authorea.com/users/351988/articles/476380-comparisonof-preemptive-and-non-preemptive-renal-transplant-recipients-with-diabetes-in-terms-ofcoronary-artery-disease-and-long-term-survival

\section{Hosted file}

Tables.docx available at https://authorea.com/users/351988/articles/476380-comparison-ofpreemptive-and-non-preemptive-renal-transplant-recipients-with-diabetes-in-terms-ofcoronary-artery-disease-and-long-term-survival

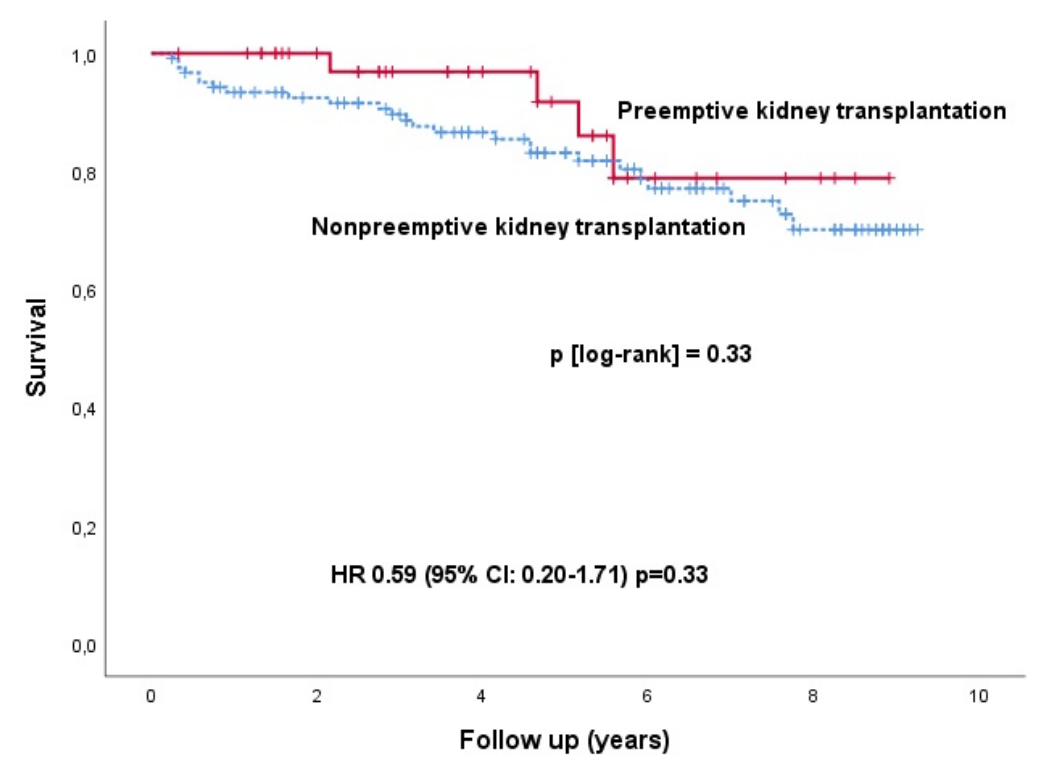

